\title{
Reconstrução do ethos em um institucional da Petrobrás
}

\author{
Reconstruction of the ethos in a Petrobrás' advertisement \\ Luis Henrique Boaventura \\ Ernani Cesar de Freitas \\ Universidade de Passo Fundo - Passo Fundo - Rio Grande do Sul - Brasil
}

$\diamond$

\begin{abstract}
Resumo: Este artigo examina a tentativa de polimento da imagem pública da empresa de capital aberto Petróleo Brasileiro S.A. (Petrobrás) por meio de uma propaganda institucional após denúncias de corrupção. Para tanto, foram tomados por base o dialogismo de Bakhtin (1997) e os estudos da cenografia e ethos por Dominique Maingueneau (2008a, 2008b, 2008c, 2008d). A análise terá foco sobre um filme institucional de um minuto de duração veiculado nacionalmente em canais de televisão brasileiros de janeiro até março de 2015, quando foi retirado do ar por uma ação do CONAR. O estudo procura demonstrar de que modo a campanha publicitária empreende uma cenografia que permite construir um discurso aparentemente genérico de superação que, na realidade, referencia obliquamente os acontecimentos recentes derivados da Operação Lava Jato, equiparando a superação de desafios históricos da empresa (como o pioneirismo na exploração de petróleo) com os "desafios" decorrentes de corrupção e ilegalidade.
\end{abstract}

Palavras-chave: Dialogismo; Mundo ético; Discurso; Cenografia; Ethos

\begin{abstract}
This article examines the attempt to polish the public image of the public company Petróleo Brasileiro SA (Petrobras) through an institutional propaganda after allegations of corruption. To this end, we took base on Bakhtin's (1997) dialogism and on scenography and ethos by Dominique Maingueneau (2008a, 2008b, 2008c, 2008d). The analysis will focus on an institutional film one minute long aired nationally on Brazilian TV from January to March 2015, when it was taken down by an action of CONAR. The study seeks to demonstrate how the advertising campaign engage a scenography that allows to build a seemingly generic speech about overcoming that actually reference obliquely recent events derived from "Operation Jet Wash", equating the overcoming of historical challenges of the company (as the pioneering exploitation of oil) with the "challenges" stemming from corruption and lawlessness.
\end{abstract}

Keywords: Dialogism; Ethical world; Speech; Scenography; Ethos

\section{Introdução}

Reconstituir a imagem de uma empresa após uma ocorrência que fere especificamente os valores por ela defendidos ao longo de sua história não é uma tarefa simples. O envolvimento da Petrobrás (ao lado de membros do governo e gigantes empreiteiras, além de empresas menores) no esquema deflagrado pela Operação Lava Jato, da Polícia Federal, em março de 2014, pegou de surpresa os que tinham na estatal Petróleo Brasileiro S.A. um exemplo de credibilidade, transparência e boa gestão em uma empresa nacional. Em se tratando de ethos, imagem percebida pelo público, a Petrobrás sempre ocupou posição de vantagem. Durante muitos anos a empresa foi "a empresa dos sonhos dos jovens para trabalhar", de acordo com pesquisa anual da consultoria Cia de Talentos, até passar a alternar o primeiro lugar nos últimos anos com o Google.

A tentativa de restaurar essa imagem passou pelo lançamento, em janeiro de 2015, da campanha "Petrobrás - Ontem, hoje e sempre superando desafios", um filme institucional de um minuto veiculado em canais de televisão no Brasil inteiro. Em março de 2015, o CONAR (Conselho Nacional de Autorregulamentação Publicitária) interveio com uma notificação à empresa, em que a acusava de equiparar os desafios históricos vencidos pela Petrobrás a denúncias de corrupção, induzindo o público a considerar que ambos se tratam de "desafios" 
da mesma natureza. A Petrobrás retirou o institucional do ar no mesmo mês.

A questão norteadora do artigo é a seguinte: o institucional "Petrobrás - Ontem, hoje e sempre superando desafios" engendra uma cenografia que busca substituir o ethos prévio mais recente da empresa (adquirido e projetado involuntariamente desde as denúncias da Operação Lava Jato) por um ethos prévio mais antigo, anterior às denúncias, representativo de valores que a empresa busca associar às próprias fibras de sua fundação (honestidade, resiliência diante de desafios, identificação com a figura do trabalhador brasileiro). O objetivo é descrever este procedimento e demonstrar os artifícios utilizados na retomada de tempos mais áureos para a empresa (rememoração de desafios históricos vencidos alternados com filmagens antigas), com a imposição de um fiador (através da persona do operário, largamente explorada ao longo do vídeo) e pela tentativa de trazer o público para dentro do mundo ético que o institucional constitui (pela empatia com o fiador e pelo uso frequente da primeira pessoa do plural).

Nosso marco teórico situa-se no dialogismo de Bakhtin (1997) e na concepção de cenografia e ethos desenvolvidos por Dominique Maingueneau (2008a, 2008b, 2008c, 2008d) no âmbito da análise do discurso. A pesquisa é descritiva e bibliográfica com abordagem qualitativa, o procedimento é observacional e o método é dedutivo. Nosso corpus de análise é o filme institucional de um minuto de duração chamado "Petrobrás - Ontem, hoje e sempre superando desafios", veiculado nacionalmente em canais brasileiros de janeiro a abril de 2015. As figuras utilizadas no artigo são imagens retiradas diretamente do vídeo quando ainda disponível no canal oficial da Petrobrás no site de compartilhamento de vídeos Youtube.

Este artigo é dividido em duas partes: um capítulo de fundamentação teórica, "1 Dialogismo e os ethé constitutivos do discurso", e um capítulo dedicado à análise do corpus, "2 A restauração de um ethos prévio", que por sua vez inclui um subcapítulo, "2.1 Um truque em três movimentos".

\section{Dialogismo e os ethé constitutivos do discurso}

O conceito moderno para o antigo ethos aristotélico (constituinte da trinca phronesis, areté e eunoia) está inexoravelmente ligado, em suas raízes, ao dialogismo do Círculo de Bakhtin e à própria Teoria Polifônica do Discurso. Conforme esclarece Ruth Amossy (2008), a integração do termo "ethos" às ciências da linguagem tem seu registro primordial na teoria polifônica da enunciação de Oswald Ducrot. O linguista francês foi um dos responsáveis, como salientam Charaudeau e
Maingueneau (2008), pela redescoberta do trabalho de Bakhtin capitaneada no início dos anos 80. Foi Ducrot o responsável por elaborar uma noção especificamente linguística da polifonia (CHARAUDEAU; MAINGUENEAU, 2008).

Cumpre lembrar que o próprio conceito de dialogismo foi tomado emprestado pelo Círculo de Bakhtin da Análise do Discurso. Conforme Charaudeau e Maingueneau (2008, p. 160), o dialogismo "se refere às relações que todo enunciado mantém com os enunciados produzidos anteriormente, bem como com os enunciados futuros que poderão os destinatários produzirem". O que fez Bakhtin (1997) foi situar a enunciação em um âmbito temporal, com amplitude e profundidade, que toma a comunicação como uma corrente ininterrupta de discursos que se sobrepõem, substituem e, acima de, referem um ao outro, ou seja: dialogam entre si.

Todo falante é por si mesmo um respondente em menor ou maior grau: porque ele não é o primeiro falante, o primeiro a ter violado o eterno silêncio do universo, e pressupõe não só a existência do sistema da língua que usa, mas também de alguns enunciados antecedentes - seus e alheios - com os quais o seu enunciado entra nessas ou naquelas relações (baseia-se neles, polemiza com eles, simplesmente os pressupõe já conhecidos do ouvinte). Cada enunciado é um elo na corrente complexamente organizada de outros enunciados (BAKHTIN, 1997, p. 272).

O dialogismo bakhtiniano e a noção de ethos desenvolvida por Maingueneau se confundem e se completam quando sobrepostos, principalmente ao se confrontar os conceitos de ethos pré-discursivo e do enunciado como "fração de uma corrente de comunicação verbal ininterrupta" (CHARAUDEAU; MAINGUENEAU, 2008). Ao mesmo tempo em que Amossy (2008) lembra a colocação do termo "ethos" no radar da Análise do Discurso por Oswald Ducrot, a linguista também destaca que o conceito foi verdadeiramente aprofundado e desenvolvido do ponto de vista da Linguística moderna por Dominique Maingueneau. No trabalho de Maingueneau (2008c), o ethos extrapola a Retórica aristotélica e ganha terreno para além do quadro de argumentação, onde vai alcançar o processo que dá conta da adesão dos sujeitos a este ou àquele posicionamento através de outros mecanismos que não o da persuasão direta através de argumentos.

Na Retórica de Aristóteles, o ethos é parte de três qualidades elementares para a produção de uma boa autoimagem do orador perante seu público: a prudência (phronesis), da ordem do logos; a virtude (areté), da ordem do ethos ("virtude", como veremos, é precisamente o que a Petrobrás procura recuperar com seu institucional); e benevolência (eunoia), da ordem do pathos. Na Análise 
do Discurso, o ethos tem sua eficácia ligada ao processo de enunciação, sem, contudo, estar explicitado no enunciado (MAINGUENEAU, 2008c). Trata-se não necessariamente dos traços de caráter que o enunciador de fato possui, mas daqueles que ele projeta em seu discurso. Conforme Barthes, citado por Maingueneau (2008c, p. 59), "o orador enuncia uma informação e ao mesmo tempo diz: eu sou isso, eu não sou aquilo". Este dizer, no entanto, surge implicitamente no enunciado (ethos mostrado), correndo abaixo da superfície do que de fato é dito pelo orador.

Como Maingueneau (2008c) destaca, este processo foi desvelado por Ducrot ao distinguir "locutor-L" e "locutor-lambda": o ethos não é dito no enunciado, ele é mostrado no ato de enunciação. Isto não através de afirmações elogiosas explícitas ("eu sou virtuoso", "eu tenho credibilidade") que o orador faria a seu respeito no corpo do discurso; tal procedimento, pelo contrário, poderia ter resultado oposto ao esperado. A eficácia do ethos passa pelos mecanismos empreendidos pelo orador para melhor projetá-lo ao público sem que este perceba que existem duas esferas distintas na troca linguageira: a imagem percebida pelo público e a imagem real, tornada inacessível a este público pelo processo de mise-en-scène. Os mecanismos utilizados para confecção dessa imagem projetada do enunciador são diversos, como a cadência da fala, a entonação, a escolha das palavras, a linha de argumentação.

Maingueneau (2008c) lembra que Bakhtin já falava em "tom" em seus trabalhos (termo apropriadamente versátil, como destacado pelo linguista, por servir tanto ao texto escrito quanto ao oral); o ethos seria, portanto, a "voz" que perpassa o texto, uma voz que fala ao interlocutor em uma frequência outrem, paralela; assim é possível que ambos, tom e conteúdo do texto, digam coisas completamente diferentes ao mesmo tempo (embora empreendida uma cenografia que projete coesão para ser aceito pelo parceiro de comunicação). A projeção do ethos envolve a exposição de uma vocalidade que avalize o enunciador e seu discurso com uma chancela positiva ou que ajude a "convencer", a persuadir o outro na direção que o orador pretende. Podemos verificar facilmente tal procedimento no universo da política, do jornalismo opinativo e do mercado publicitário. A publicidade, em especial, como veremos na análise do corpus, é pródiga em lançar mão de meios de cenografia para direcionar seu público em determinado curso (comprar determinado produto, reforçar uma característica de imagem da instituição ou mesmo reverter um problema de imagem contraído pela empresa).

O conceito de ethos em Maingueneau está estritamente ligado a Bakhtin, sobretudo quando investigamos a distinção que Maingueneau opera entre o ethos discursivo e o ethos pré-discursivo (detalhados a seguir). A "virtude" que o orador projeta não entra em ação apenas a partir do momento da enunciação do discurso, do mesmo modo que, ao ouvir um discurso político ou assistir a um comercial de um produto, não processamos as palavras ditas como se as ouvíssemos pela primeira vez. Há uma base de informações previamente estabelecidas a partir da qual o público começa ao receber um discurso, como o partido que determinado político integra ou sua opinião sobre este político, sobre o produto anunciado, sobre a empresa que o fabrica; todos os discursos e comerciais anteriores já veiculados a respeito e a própria relação que o público vem mantendo com o político ou com a empresa possuem peso na recepção do novo discurso.

Transitar entre a noção de ethos de Maingueneau e o dialogismo bakhtiniano é natural, orgânico. Como posto por Bakhtin (1997, p. 316), "o enunciado deve ser considerado acima de tudo como uma resposta a enunciados anteriores. O enunciado é sempre, em menor ou maior grau, uma resposta". Todo enunciado surge dentro de um contexto social e histórico onde está depositada, elipticamente, a corrente enunciativa que compõe a identidade social e cultural do orador e de seu público. Segundo Bakhtin, citado por Charaudeau e Maingueneau (2008, p. 161),

a orientação dialógica é, bem entendido, um fenômeno característico de todo o discurso [...]. Em todos os caminhos que levam a seu objeto, o discurso encontra o discurso de outrem e estabelece com ele interação viva e intensa. Somente o Adão mítico, abordando com o primeiro discurso um mundo virgem e anda não dito, o solitário Adão, poderia verdadeiramente evitar absolutamente essa reorientação mútua em relação ao discurso de outrem, que se produz no percurso do objeto

Considerando esta abordagem a partir da perspectiva de Maingueneau, a ressonância dialógica de Bakhtin ajuda a compor, para o público, o ethos pré-discurivo que ele conserva do enunciador. Maingueneau (2008b) faz a divisão entre ethos discursivo e ethos prévio da seguinte forma:

- Ethos pré-discursivo ("ethos prévio", conforme trata Ruth Amossy (2008) e como passaremos a adotar neste artigo): a opinião que o destinatário possui do enunciador antes da efetividade do discurso e que, de algum modo, antecipa sua enunciação. No caso do discurso publicitário, há um ethos prévio construído por campanhas publicitárias anteriores referentes à empresa ou marca em questão, e mesmo à relação pessoal de cada indivíduo com esta marca. A agência de publicidade contratada para elaboração de uma campanha tem como tarefa básica levar em consideração a imagem residual 
que todas as campanhas prévias ajudaram a construir. $\mathrm{O}$ próprio fato de que o discurso está situado no âmbito da publicidade pode gerar determinado efeito não planejado que os responsáveis pela campanha devem prever (o fato de que um institucional de uma empresa é um discurso oficial, e este institucional ser usado para negar ou reverter veladamente uma situação, possui determinado efeito sobre o público, como investigaremos na análise). De acordo com Maingueneau (2008b, p. 71), "o simples fato de que um texto pertence a um gênero de discurso ou a um certo posicionamento ideológico induz expectativas em matéria de ethos".

- Ethos discursivo: o ethos que se constrói na efetividade do discurso. Conforme Ducrot, mencionado por Maingueneau (2008a, p. 71), "[trata-se] da aparência que lhe confere a fluência, a entonação, calorosa ou severa, a escolha das palavras, dos argumentos [...]". É pela projeção do ethos construído no nível do discurso que o enunciador vai procurar avalizar sua enunciação e confirmar ou infirmar determinados aspectos do ethos prévio para impor ao público um comportamento específico.

O ethos prévio e o ethos discursivo entram em jogo no âmbito do discurso enquanto mise-en-scène, enquanto forma de encenação. "Não podemos, pois, contentar-nos, como a retórica tradicional, em fazer do ethos um meio de persuasão: ele é parte constitutiva da cena de enunciação [...]" (MAINGUENEAU, 2008b, p. 75). Por "cena de enunciação", Maingueneau (2008c) entende três tipos de cenas que a compõem:

- Cena englobante: atribui ao discurso um estatuto pragmático, integrando-o em um tipo: publicitário, administrativo, filosófico... Nosso corpus de análise se situa no discurso de tipo publicitário.

- Cena genérica: a do contrato associado a um gênero ou subgênero do discurso: o editorial, o sermão, o guia turístico, a consulta médica... Neste caso da Petrobrás, o veículo do discurso é a propaganda institucional.

- Cenografia: não é imposta pelo gênero, mas construída pelo próprio texto. O discurso é articulado para impor determinado comportamento, e disposto em uma cena que ajude a validá-lo e a cumprir com a eficácia do ethos que o institucional da empresa pretende projetar para o público.

Maingueneau (2008b, p. 76) explica que a adoção do termo cenografia se deve ao seu "duplo valor: (1) Acrescentando à noção teatral de 'cena' a de -grafia, da 'inscrição' [...] (2) consideramos o desenvolvimento da enunciação como a instauração progressiva de seu próprio dispositivo de fala". Isto significa que a lógica da cenografia costurada por Maingueneau diz respeito a um sistema que deve, ao mesmo tempo, outorgar o discurso que o constitui e por ele ser outorgado. Trata-se, como define o linguista, de um processo de enlaçamento.

Desde sua emergência, a fala é carregada de certo ethos, que, de fato, se valida progressivamente por meio da própria enunciação. A cenografia é, assim, ao mesmo tempo, aquilo de onde vem o discurso e aquilo que esse discurso engendra: ela legitima um enunciado que, por sua vez, deve legitimá-la, deve estabelecer que essa cena da qual vem a palavra é precisamente a cena requerida para enunciar nessa circunstância. (MAINGUENEAU, 2008b, p. 71, grifo do autor)

Conquistar a adesão do público ao discurso do enunciador envolve projetar um ethos que, além de inspirar uma relação empática entre as partes, crie as condições para que este público possa não apenas compreender, mas também participar do mundo particular, de conceitos e de ideias, que está sendo engendrado pelo discurso. Para tanto, é preciso haver a incorporação, pela qual, como coloca Maingueneau (2008c, p. 65), “o destinatário em posição de intérprete [...] se apropria desse ethos". Todo discurso, seja oral ou escrito, possui uma vocalidade que permite relacioná-lo a uma fonte enunciativa (MAINGUENEAU, 2008b). A vocalidade subscrita em cada discurso corporifica o enunciador, dando forma a um "fiador" que atesta o que é dito. Atribui-se ao fiador um "caráter" (feixe de traços psicológicos) e uma "corporalidade" (compleição física e modo de se vestir). O destinatário se apropria do ethos (forma de mover-se no espaço social do fiador) através do que Maingueneau (2008b) chama de incorporação. Como Maingueneau (2008a) explica, essa incorporação atua em três registros indissociáveis: (1) a enunciação do texto dota o fiador de uma determinada corporalidade; (2) o co-enunciador incorpora, ou seja, assimila uma série de mecanismos e movimentos que correspondem à forma como este fiador se relaciona com o mundo; e (3) estas incorporações dão origem a outra corporalidade, da comunidade imaginária dos que aderem àquele discurso.

O espaço de argumentos, ideias e linhas de raciocínio construído pelo discurso é chamado de "mundo ético" por Maingueneau (2008c), um mundo ao qual o enunciador deve conceder acesso no papel de "fiador", cuja responsabilidade é atestar o que é enunciado. Maingueneau relê aqui o conceito bakhtiniano de ato ético, que Bakhtin (1997) compreende como a ocupação de um lugar ímpar no mundo, a partir do qual o sujeito contrai a responsabilidade de responder por seus atos. Como o fiador está relacionado a uma dinâmica corporal, o co-enunciador não decodifica o sentido, mas participa "fisicamente" deste mundo acessado por intermédio do fiador. O fiador é moldado de acordo com um caráter e 
uma corporalidade. "O caráter corresponde a um feixe de traços psicológicos. Quanto à corporalidade, ela é associada a uma compleição física e a uma forma de se vestir" (MAINGUENEAU, 2008c, p. 65). Como veremos, o institucional da Petrobrás analisado procura estabelecer determinadas figuras, símbolos de certos valores que a empresa pretende defender ou a eles associar sua imagem, que recebem, através de atores inseridos em certa cenografia, uma corporalidade específica. Estas figuras são acionadas pela cenografia do institucional como fiadoras do mundo ético que a Petrobrás pretende engendrar e para o qual busca trazer seu público (um mundo onde a empresa é correta, bem gerida e resiliente, e onde escândalos de corrupção são tratados como contratempos gerenciais e desafios a serem superados).

Maingueneau (2008b) também explora a questão do modelo $\times$ antimodelo de mundo ético. Da mesma forma que o fiador utiliza-se de um ethos para validar seu discurso, para fazer adentrar a um mundo em que suas palavras são pertinentes, é possível que o enunciador se utilize de um antimodelo para contrapor um modelo que se quer validar, um antifiador para acentuar a pertinência do fiador que se engendra para cativar ("capturar") o público. Maingueneau (2008b) trata de uma cena a se contrapor como "cena validada", ou seja, já instalada na memória coletiva, compartilhada pelos membros de uma comunidade. Emediato (2008:90) chama este tipo de validação de "pré-validação nas situações de comunicação monolocutivas, como é o caso das mídias". Assim, em uma propaganda eleitoral, um candidato da oposição pode usar um cenário atual de crise como antimodelo do cenário que pretende implementar em seu mandato, estabelecendo no candidato da situação seu antifiador. Tal noção, como vamos verificar, é importante por se tratar de procedimento corrente quando se pretende operar a validação de um mundo ético, portanto é relevante notar tanto quando tal estratégia é utilizada como quando é deliberadamente negligenciada, o que ocorre aqui.

\section{A restauração de um ethos prévio}

Sabemos que a publicidade é uma generosa fonte de exemplos de construções de cenografia para a Análise do Discurso, mas o caso da campanha "Petrobrás - Ontem, hoje e sempre superando desafios" é uma oportunidade particularmente singular e provocante para pesquisadores empenhados em desvendar os jogos de incorporação, ressonância dialógica e projeção de mundo ético. Isto porque não se trata de uma peça publicitária comercial, corpus frequente de trabalhos na área, elaborado a fim de vender um produto (de persuadir o público nesta direção: a do impulso da compra), assim como também não se trata de um institucional como outros (principalmente como outros da própria Petrobrás), em que se visa a um reforço ou renovação da imagem da marca.

A campanha é a resposta da Petrobrás (discurso oficial) ao público que vem assistindo por longos meses a um escândalo de corrupção que atinge uma empresa tida até então pela opinião pública como idônea, bem administrada e muito bem-sucedida. É de conhecimento geral que a Petrobrás já experimentou outros casos com potencial para ferir sua imagem ao longo de sua história, como vazamentos e acidentes ecológicos ou o escândalo de roubo de 1989 denunciado pelo jornalista Ricardo Boechat, mas as consequências deflagradas pela Operação Lava Jato ${ }^{1}$, da Polícia Federal, são sem precedentes, como a queda acentuada de ações e a troca no comando da empresa.

Com sua imagem abalada e demanda por uma resposta à opinião pública, a Petrobrás lançou em janeiro de 2015 uma campanha publicitária em que, sem citar explicitamente as irregularidades vindas a público, trata sobre como a empresa segue superando desafios e aprimorando sua governança. Em março de 2015, a $2^{\text {a }}$ Câmara do Conselho de Ética do CONAR (Conselho Nacional de Autorregulamentação Publicitária) considerou que os desafios que a empresa enfrenta atualmente, decorrentes de denúncias de corrupção, não podem ser tratados de modo equivalente aos desafios históricos superados pela empresa (como a exploração bem-sucedida de novas fontes de petróleo). Diante da notificação, a Petrobrás suspendeu a campanha no rádio e na televisão e retirou o vídeo de sua conta oficial no Youtube, embora ainda mantenha um site (superacao. hotsitespetrobras.com.br) em que faz conhecer suas providências diante das denúncias sem nunca se desfazer da palavra-chave: "superação".

A análise que se segue pretende demonstrar de que modo a campanha procurou substituir o ethos prévio mais recente, de uma empresa em franca desvalorização e com problemas de corrupção em sua alta gerência, pelo ethos estabelecido previamente (ethos prévio mais antigo) à divulgação dos dados da Operação Lava Jato, que espelhava uma empresa como modelo de gestão, superação e identificação com a figura do cidadão brasileiro. Um processo de restauração da confiança na marca.

Como sabemos que o ethos depende em boa parte da relação empática construída entre enunciador e público (o ethos deve de alguma forma reproduzir características do público para ser recebido de modo eficaz), há um tentativa de instituir um fiador para o mundo ético construído pelo

\footnotetext{
1 Operação realizada pela Polícia Federal e divulgada a partir de março de 2014 com o objetivo de apurar um esquema de lavagem de dinheiro em que foram envolvidos nomes fortes do governo e grandes empresas, como a construtora OAS e a Petrobrás.
} 
discurso que espelhe a persona do trabalhador brasileiro, ao lado de marcas textuais características como "nossa gente", em que o enunciador chama o público a participar do seu mundo ético pelo uso indiscriminado da primeira pessoa do plural. Contudo, como veremos, a tentativa de substituição do ethos atual pelo ethos prévio não é bem-sucedida e a campanha tem má recepção da opinião pública, reação negativa do CONAR e consequente retirada da propaganda institucional dos meios de comunicação.

\subsection{Um truque em três movimentos}

A Petrobrás sempre representou um oásis de prestígio e credibilidade no meio empresarial brasileiro. Como uma companhia que tem parte de seu capital aberto, aparentar solidez financeira, transparência e confiança, atributos da ordem do ethos ("virtude"), são características fundamentais com reflexo direto nos balanços financeiros da empresa. Imagem não é apenas reflexo de uma trajetória bem-sucedida, é diferencial competitivo e condição para manutenção do sucesso.

Contudo, os meses que se seguiram à divulgação da Operação Lava Jato, em março de 2014, com o envolvimento crescente de empreiteiras, membros do governo federal e da alta gerência da Petrobrás a cada novo ponto conectado na trama, deixaram na empresa um rastro de destruição: queda da presidente Graça Foster e outros membros da gerência, resultado líquido negativo de 21 bilhões de reais em 2014 e danos inestimáveis à imagem da empresa. A Operação trouxe à Petrobrás um novo ethos, indesejado, substituindo o antigo, de uma empresa idônea e confiável. A campanha publicitária lançada no início de 2015 tinha por objetivo desfazer a troca: não produzir um ethos inteiramente novo, mas retomar o ethos prévio que a empresa mantinha até antes da divulgação das denúncias.

Este processo pode ser explicado do ponto de vista da cenografia de Maingueneau (2008a, 2008b, 2008c, 2008d), mas possui ligações claras com o dialogismo de Bakhtin (1997). Como notoriamente foi colocado por Bakhtin (1997), o locutor não é o Adão bíblico, perante objetos virgens, ainda não designados, os quais é o primeiro a nomear. Todo objeto de discurso já foi falado por outros locutores, já foi enunciado outras vezes. O objeto de seu discurso torna-se ponto onde se encontram as opiniões de interlocutores imediatos, ou os diferentes discursos de um mesmo enunciador. $\mathrm{O}$ enunciado está voltado não só para o seu objeto, mas também para o discurso do outro acerca daquele objeto e para outros discursos daquele enunciador. A Petrobrás ativa este procedimento ao resgatar discursos bem-sucedidos (da empresa como orgulho nacional, como exemplo de credibilidade, como pródiga em superar desafios) de outros tempos, de ethé mais positivos.

Este ethos prévio que se busca recuperar tem origem no que Maingueneau (2008b, p. 81) chama de cena validada, "em que 'validada' significa 'já instalada na memória coletiva', seja como antimodelo, seja como modelo valorizado". No caso do institucional, trata-se de valorizar o modelo previamente estabelecido (imagem de empresa-modelo instalada na memória coletiva), mas substituído involuntariamente em função das ocorrências de corrupção. Temos, desta forma, dois ethos prévios com que o institucional tenta interagir para estabelecer seu ethos discursivo:

- Ethos prévio mais antigo: uma empresa-modelo, anunciada ostensiva e frontalmente em seus institucionais como um motivo de orgulho nacional (inclusive explorada midiaticamente como vitrine do potencial econômico brasileiro e cujo sucesso sempre se tentou vincular -junto à opinião pública - à capacidade gestora do próprio Governo Federal).

- Ethos prévio mais recente: uma empresa corroída pela ilegalidade e minada pela desconfiança dos investidores após ser ligada ao escândalo das denúncias do Lava Jato.

O objetivo é o de substituir ou amenizar o ethos prévio mais recente em detrimento de uma revalorização do ethos prévio mais antigo. $\mathrm{O}$ texto narrado da propaganda, de um minuto de duração, foi transcrito integralmente a seguir:

\footnotetext{
Superação - desde o começo nossa história está repleta dessa palavra. Lá atrás, quando diziam que não existia petróleo no Brasil, a nossa gente mostrou pro mundo que ele existia sim, e que era nosso. Década após década, desafio após desafio, seguimos em frente. Recentemente fizemos uma descoberta que surpreendeu o mundo: o pré-sal. Hoje os desafios são outros, por isso estamos aprimorando a governança e a conformidade da gestão. Seja qual for o desafio, a nossa melhor resposta sempre será aquela palavra que nos acompanha desde o começo: superação. Essa é a Petrobrás. Ontem, hoje e sempre superando desafios. Todos eles. (PETROBRÁS, 2015)
}

A cenografia empreendida nesse procedimento pode ser verificada através de algumas marcas linguísticas no texto do institucional e na interação entre texto e imagem.

- O institucional abre com imagens em plano aberto das plataformas petrolíferas em alto mar e com a palavra "superação", em letras garrafais, projetada contra um oceano em intenso movimento;

- Na sequência, em "Lá atrás...", surgem filmagens antigas do princípio da extração petrolífera da 
Petrobrás (imagens em preto-e-branco ou com cores gastas);

- Em "a nossa gente...", surge uma tela dividida entre uma embarcação e um trabalhador braçal (figura altamente empática, representativa do povo) se esforçando para girar uma manivela;

- Em "seguimos em frente", voltamos ao tempo contemporâneo com a imagem de um rio curvilíneo;

- Em "hoje os desafios são outros", surge a imagem de um painel eletrônico mostrando cotações na bolsa de valores;

- Em "aprimorando a governança e a conformidade da gestão", frase-chave do institucional, são usadas imagens vagas de navios da empresa. Simbolicamente (embora, por certo, tal simbolismo tenha sido acidental), segue-se um plano aéreo que mostra o oceano sob algumas nuvens e os navios da empresa diminutos no terço inferior do quadro ("à deriva" é uma legenda fácil de associar à imagem);

- Em "seja qual for o desafio", em outro desenrolar que embora simbólico provavelmente não foi intencional, o sol se põe e a Petrobrás vê seu anoitecer se aproximar;

- O "todos eles" final coloca ênfase irrevogável sobre de que tipo de desafio a Petrobrás realmente trata em seu institucional, embora evite palavras que remetam explicitamente às denúncias.

A Petrobrás tem um problema de imagem, e o papel de um institucional consiste precisamente em polir a imagem da empresa. Para isso, a campanha procura realizar um procedimento aparentemente simples, mas que se revela o oposto exatamente pela frontalidade do "truque": substituir, no imaginário coletivo, o ethos prévio recente pelo ethos prévio mais antigo. Este truque é operado a partir de três movimentos:

1. A recuperação de imagens antigas de plataformas petrolíferas da empresa com a narração que valoriza seu pioneirismo na exploração, acenando para o desejo de retomar um passado mais brilhante;

2. A tentativa de constituir empatia com o público pelo uso indiscriminado da primeira pessoa do plural; o objetivo é o de incluir o público neste processo de "aprimoramento da governança e da conformidade na gestão", deixando implícito que o petróleo é "nosso", a Petrobrás é "nossa", e seus problemas, não por menos, são "nossos" também;

3. Estabelecer, na figura do trabalhador braçal (brasileiro, honesto, habituado a superar desafios, dignificado pelo esforço do trabalho duro), um fiador para o mundo ético que a campanha engendra.
A seguir ilustramos cada um destes três passos com imagens retiradas do institucional quando ainda disponível no canal oficial da Petrobrás no Youtube.

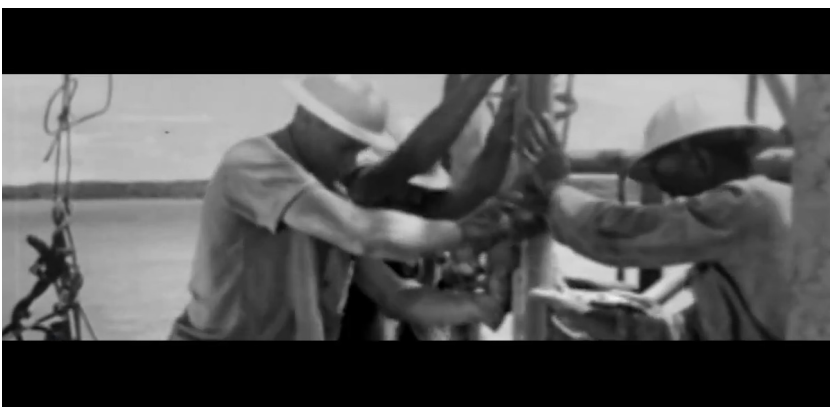

Figura 1. "Lá atrás..."

Fonte: <youtube.com/user/canalpetrobras>, 2015

Como posto por Bakhtin (1997, p. 291) em sua perspectiva dialógica do discurso, "cada enunciado é um elo da cadeia muito complexa de outros enunciados". A fuga possível deste presente disruptor que vive a Petrobrás só pode ser para seu próprio passado, composto de outros enunciados mais positivos (usados inclusive em institucionais antigos, anteriores às consequências do Lava Jato), um passado de que a empresa se orgulha pelo pioneirismo na exploração de petróleo na costa brasileira e pelo sucesso ao se estabelecer como uma gigante do ramo em plena América Latina (o que representa desvantagem geográfica quando o assunto é exploração e extração de combustíveis fósseis). Conforme Bakhtin e Voloshinov, citados por Charaudeau e Maingueneau (2008, p. 161),

toda enunciação, por mais significante e completa que ela seja por si mesma, constitui apenas uma fração de uma corrente de comunicação verbal ininterrupta [...]. No entanto, essa comunicação verbal ininterrupta constitui, por sua vez, apenas um elemento da evolução ininterrupta de um grupo social dado.

O crescimento da Petrobrás também é frequentemente ligado ao crescimento do próprio Brasil, aspecto valorizado no institucional pela noção frequentemente referenciada de que a empresa foi construída pelos brasileiros com suas próprias mãos (a ênfase no trabalho braçal é uma constante do vídeo).

Ao mesmo tempo, a narração contempla um tom de orgulho nacional quase setentista ao afirmar que "quando diziam que não existia petróleo no Brasil, a nossa gente mostrou pro mundo que ele existia sim, e que era nosso" (PETROBRÁS, 2015). Ligar a imagem da Petrobrás a uma flama nacionalista significa apelar para um sentimento telúrico de pertencer ao mesmo país, ao mesmo lugar, à mesma terra, em torno da qual os indivíduos sob o mesmo 
"estandarte" (o de "brasileiros") devem se unir para defender uma cria da sua pátria (Petrobrás, "brasileira").

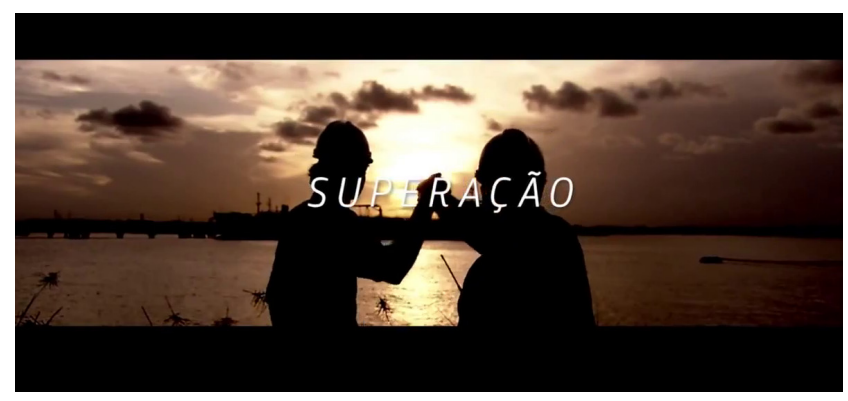

Figura 2. "O petróleo é nosso"

Fonte: <youtube.com/user/canalpetrobras>, 2015.

O discurso de que "o petróleo é nosso" é muito antigo na história da Petrobrás - data dos primeiros anos da estatal e tem origem no sentimento nacionalista incutido pela ditadura militar. Em sua cenografia, o institucional procura trazer o público para dentro de seu mundo ético, e parte deste objetivo é perseguida através do uso da primeira pessoa do plural, como já era frequente nos institucionais da empresa mesmo antes da Operação Lava Jato. As imagens que se seguem mostram funcionários da empresa realizando trabalho em equipe; a palavra "superação" volta a aparecer no final do vídeo, sobre dois trabalhadores que se cumprimentam diante de um pôr-do-sol.

A Petrobrás busca associar sua cenografia (a narração associada às imagens que surgem na tela), e especificamente suas palavras, ("superação", "pré-sal", "nossa gente") com ethé prévios positivos depositados na memória do público como cena validada, como destaca Bakhtin (1997, p. 314), a expressividade da palavra "se prende quer à expressividade padrão de um gênero, quer à expressividade individual do outro que converte a palavra numa espécie de representante do enunciado do outro em seu todo". O uso de palavras-chave como "superação" busca expressão dentro do enunciado em que são usadas na esperança de que seu valor positivo influencie o todo do discurso recebido pelo espectador (e, portanto, o ethos da empresa).

É interessante como as primeiras ocorrências do texto se relacionam com as posteriores. $\mathrm{O}$ institucional pode ser dividido em duas partes: na primeira, retomam-se exemplos de superação no passado, história da construção e crescimento de uma empresa na qual o público (que se confunde intensamente com "povo" na propaganda, embora a palavra não apareça explicitamente) é envolvido; na segunda, busca-se mostrar o que a Petrobrás fará e está fazendo para superar seu "novo" desafio, e desta parte, o que é importante rever, o público também é convidado a participar, embora não tenha responsabilidade direta sobre as denúncias de corrupção que a empresa sofre. Neste sentido, o "nossa história", "nossa gente" e "que era nosso" ocupam, de modo forçado, o mesmo espectro que "estamos aprimorando a governança" e "nossa melhor resposta", medidas de resposta às denúncias que não são de responsabilidade do público, mas pelo contrário, estão sendo exigidas por ele.

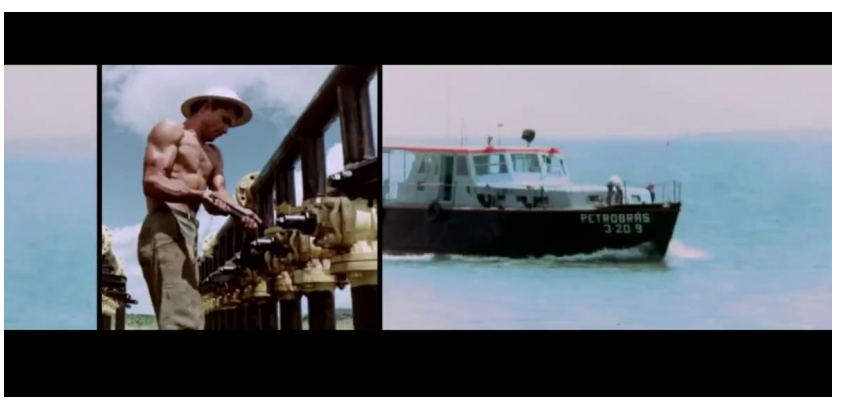

Figura 3. "Nossa gente"

Fonte: <youtube.com/user/canalpetrobras>, 2015.

A presença do trabalhador braçal é massiva por todo o vídeo. Como a empresa não possui um rosto propriamente dito (geralmente tal rosto lhe é emprestado por seu CEO, uma associação que não beneficia o ethos da Petrobrás no momento), é notável que, desde o começo do comercial, a Petrobrás procura estabelecer um vínculo de empatia entre ela e o espectador através do retrato do trabalhador da empresa, que é representado como o brasileiro honesto, o operário, executor de tarefas físicas. Há aí uma oposição lógica que o institucional apresenta pela ênfase em uma figura e pela supressão de outra: a do executivo, do ocupante do cargo de gerência, grande alvo das denúncias deflagradas na Operação Lava Jato. Em nenhum momento a persona do executivo da Petrobrás se mostra. O institucional é povoado de funcionários de chão de fábrica, ligados ao mito do trabalho duro como fonte edificante de caráter. Opõe-se, portanto, a dignidade do esforço físico no trabalho contra o dinheiro fácil do colarinho branco.

O fiador para este mundo que a empresa procura criar com seu institucional (um "portal" para o passado da empresa, ou o passado percebido pela opinião pública) é a própria figura do trabalhador brasileiro, em quem, esperase, o espectador tratará de se espelhar, sobretudo quando reforçado pelo texto que trata o tempo todo de verbos na 1 a pessoa do plural. Como lembra Maingueneau (2008c, p. 58), "a persuasão só é obtida se o auditório constatar no orador o mesmo ethos que vê em si mesmo". O petróleo, afinal de contas, "é nosso".

Percebemos, contudo, que o ethos visado era o de reafirmação do ethos prévio mais antigo, mas o ethos 
efetivamente produzido (involuntariamente) corresponde à empresa tentando fintar ou amenizar fatos importantes de sua realidade; ou seja, há um ethos negativo produzido involuntariamente pela propaganda, conforme percebido não somente pelo público, mas pelo CONAR por meio de sua decisão de notificar a Petrobrás. Ou seja, o institucional falha em substituir o ethos prévio negativo mais recente por um ethos prévio positivo mais antigo, selecionado como cena validada a partir da memória coletiva que o público compartilha da história da empresa, o que leva o ethos efetivo que é produzido, "aquele que, pelo discurso, os co-enunciadores, em sua diversidade, construirão" (MAINGUENEAU, 2008b:82), ser um ethos negativo, indo de encontro às expectativas da Petrobrás com a campanha.

\section{Considerações finais}

Buscamos descrever neste artigo a cenografia empreendida pelo institucional "Petrobrás — Ontem, hoje e sempre superando desafios" para recuperação da imagem pública da empresa diante das denúncias de envolvimento no esquema de lavagem de dinheiro deflagrado pela Operação Lava Jato. Para tanto, utilizamos como marco teórico o dialogismo bakhtiniano (BAKHTIN, 1997) e a concepção de ethos em Maingueneau (2008a, 2008b, 2008c, 2008d), especificamente as noções de fiador, mundo ético e ethos pré-discursivo.

A campanha da estatal tem por objetivo substituir o ethos prévio mais recente, um ethos mostrado, de modo involuntário, depois do início da fase ostensiva da operação da Polícia Federal, por um ethos mais positivo. Este segundo ethos, objetivo da campanha, não seria construído de modo puro e original (tal concepção de originalidade vai de encontro à raiz mais elementar do que nos fala Bakhtin a respeito da ressonância dialógica dos enunciados); pelo contrário, seria selecionado estrategicamente, como cena validada, dos ethé prévios mais antigos que constituem a trajetória da empresa. Historicamente, a Petrobrás possui uma imagem de resiliência, superação diante de desafios aparentemente intransponíveis, de estabelecimento enquanto empresa petrolífera em uma parte do mundo onde se duvidava da própria existência do petróleo.

Observamos que o institucional arquiteta sua cenografia em três movimentos: (1) retomada de um passado positivo ao associar os desafios atuais, decorrentes de um escândalo de corrupção, com os desafios históricos da empresa; (2) firmar empatia com o público através do uso constante da primeira pessoa do plural com o "nossa gente", "nossa história" e a valorização do antigo discurso de que "o petróleo é nosso"; e (3) estabelecer um fiador na figura do operário braçal, dignificado pelo mito do poder purificador do trabalho enquanto esforço físico, beneficiado em especial pela oposição imediata em relação ao dinheiro fácil dos crimes do colarinho branco (figuras em posição de gerência são omitidas no institucional em detrimento da exploração do funcionário de baixa posição hierárquica).

Verificamos que, por fim, a campanha foi ineficaz em resgatar o ethos prévio mais conveniente, ligado aos valores associados historicamente à estatal, e acabou por produzir um ethos efetivo negativo, dado a rejeição experimentada do público, a notificação do CONAR e a consequente retirada do institucional tanto dos canais de televisão quanto das mídias sociais.

\section{Referências}

AMOSSY, Ruth. Da noção retórica de ethos à análise do discurso. In: AMOSSY, Ruth (Org.). Imagens de si no discurso: a construção do ethos. São Paulo: Contexto, 2008. p. 9-28.

BAKHTIN, Mikhail. Estética da criação verbal. São Paulo: Martins Fontes, 1997.

CHARAUDEAU, Patrick; MAINGUENEAU, Dominique. Dicionário de análise do discurso. São Paulo, 2008.

EMEDIATO, Wander. Os lugares sociais do discurso e o problema da influência, da regulação e do poder nas práticas discursivas. In: PROENÇA LARA, Glaucia Muniz; MACHADO, Ida Lucia; EMEDIATO, Wander(Orgs.). Análises do discurso hoje. Rio de Janeiro: Nova Fronteira, 2008. v. 1, p. 71-91.

MAINGUENEAU, Dominique. A propósito do ethos. In.: MOTTA, Ana Raquel; SAlGADO, Luciana. (Orgs.). Ethos discursivo. São Paulo: Contexto, 2008a. p. 11--29.

MAINGUENEAU, Dominique. Ethos, cenografia, incorporação. In: AMOSSY, Ruth (Org.). Imagens de si no discurso: a construção do ethos. São Paulo: Contexto, 2008b. p. 69-92.

MAINGUENEAU, Dominique. Problemas de ethos. In: POSSENTI, Sírio; SOUZA-E-SILVA, Maria Cecília Perez de (Orgs.). Cenas da enunciação. São Paulo: Parábola Editorial, 2008c. p. 55-73.

MAINGUENEAU, Dominique. Polifonia e cena de enunciação na pregação religiosa. In: PROENÇA LARA, Glaucia Muniz; MACHADO, Ida Lucia; EMEDIATO, Wander (Orgs.). Análises do discurso hoje. Rio de Janeiro: Nova Fronteira, 2008d. v. 1. p. 199-218.

PETROBRÁS. Ontem, hoje e sempre superando desafios. 2015. Disponível em: <youtube.com/user/canalpetrobras>.

Recebido: 25 de agosto de 2015

Aprovado: 20 de novembro de 2015

Contato: luishboaventura@hotmail.com nanicesar@terra.com.br 